\title{
Prospects of Nanostructure-Based Solar Cells for Manufacturing Future Generations of Photovoltaic Modules
}

\author{
N. Gupta, ${ }^{1}$ G. F. Alapatt, ${ }^{1}$ R. Podila, ${ }^{2}$ R. Singh, ${ }^{1}$ and K. F. Poole ${ }^{1}$ \\ ${ }^{1}$ Center for Silicon Nanoelectronics and Holcombe, Department of Electrical and Computer Engineering, \\ Clemson University, Clemson, SC 29634-0915, USA \\ ${ }^{2}$ Department of Physics and Astronomy, Clemson University, Clemson, SC 29634-0915, USA
}

Correspondence should be addressed to R. Singh, rajendra.singh@ces.clemson.edu

Received 22 April 2009; Revised 9 July 2009; Accepted 15 August 2009

Recommended by Mohamed Sabry Abdel-Mottaleb

\begin{abstract}
We present a comprehensive review on prospects for one-, two-, or three-dimensional nanostructure-based solar cells for manufacturing the future generation of photovoltaic (PV) modules. Reducing heat dissipation and utilizing the unabsorbed part of the solar spectrum are the key driving forces for the development of nanostructure-based solar cells. Unrealistic assumptions involved in theoretical work and the tendency of stretching observed experimental results are the primary reasons why quantum phenomena-based nanostructures solar cells are unlikely to play a significant role in the manufacturing of future generations of PV modules. Similar to the invention of phase shift masks (to beat the conventional diffraction limit of optical lithography) clever design concepts need to be invented to take advantage of quantum-based nanostructures. Silicon-based PV manufacturing will continue to provide sustained growth of the PV industry.
\end{abstract}

Copyright (c) 2009 N. Gupta et al. This is an open access article distributed under the Creative Commons Attribution License, which permits unrestricted use, distribution, and reproduction in any medium, provided the original work is properly cited.

\section{Introduction}

Globally the photovoltaic (PV) market grew 110\% last year and reached a record $5.95 \mathrm{GW}$ in 2008 [1]. It is also predicted that by 2012 more than 20 GW PV systems will be installed. Gartner has predicted an increase in PV industry revenue to $\$ 34$ billion within the next five years from $\$ 15.8$ billion in 2008 [2]. Currently, wafer-based silicon (single crystal, poly crystalline, and multicrystalline) solar cells and thin film solar cells based on amorphous silicon, $\mathrm{CdTe}, \mathrm{CuInGaSe}{ }_{2}$, and III-V semiconductors dominate PV manufacturing [3]. For future generations of solar cells a number of approaches are being explored [4]. An examination of the current literature shows that most of these solar cells are based on one-, two-, or three-dimensional structures with nanodimensions $(<100 \mathrm{~nm})$. The R\&D work related to the nanostructures falls under the buzz word of "nanotechnology" and there are questionable claims on the scientific facts [5]. As an example, the publication of a research paper on multiexciton generation in colloidal silicon nanocrystals [6] motivated the author of [7] to claim that silicon nanocrystals-based solar cells can generate two electrons from one photon, and single junction solar cell efficiencies as high as $40 \%$ are possible. The fact is that multiple exciton generation phenomena observed in nanocrystals or quantum dots have no direct relevance to the operation of the solar cell. The incorrect assumption that multiple electron hole pairs (EHPs) generation will improve the solar cell efficiency ignores the fact that the collection of the carriers is a necessary part of the solar cell operation. This can impact the further direction of basic research that is generally funded by public money [8] as well as investment of private money for establishing new photovoltaic businesses. In the broader sense of green electricity generation our objective is to examine critically all the current PV approaches that are under investigation.

PV manufacturing has its origin in semiconductor manufacturing and most of the thin film PV manufacturing (use of large glass substrate) has its origin in liquid crystal display (LCD) manufacturing. Based on an examination of the fundamentals of materials, devices, and the experience 
of semiconductor manufacturing, LCD manufacturing, and related manufacturing, it is possible to examine the prospects of incorporating nanostructure-based solar cells into PV manufacturing for next generation solar cells. Recently, a number of review papers on applications of nanostructures in solar cells have been published [3,9-18]. However, none of these papers address the issues related to manufacturing of next generations of PV modules. The objective of this paper is to critically examine the published work and point out the suitability or nonsuitability of the particular nanostructure for future generations of photovoltaic module manufacturing. In the following section, we provide the background material which is essentially required to make PV systems a significant source of electricity generation. In the third section, we examine the theoretical and experimental results associated with the materials and devices of nanostructurebased future generation of solar cells. The discussion of the paper is presented in Section 4. Finally, the paper is concluded in Section 5.

\section{Background Material}

In order to create huge PV markets, the following selection criterion must be used in the selection of appropriate technology: (i) no material supply constraint, (ii) low cost of ownership, (iii) low production cost, (iv) prospects of further cost reduction, and (v) green manufacturing with no environmental safety and health issues. In a previous publication [3], we have discussed these points in depth however for completeness key points are briefly discussed in this section.

2.1. No Material Supply Constraints. Just after oil embargo of 1973 [19], a number of semiconductor materials were proposed as the potential materials for manufacturing solar cells. In 1980, one of us published an article on the economic requirements for new materials for solar cells and predicted that silicon is the best material for large-scale PV manufacturing [20]. Over the last 29 years our prediction has been correct, since more than $90 \%$ solar cells manufactured in 2008 are made out of silicon. Thus it is quite relevant to go back to our 1980 paper and rewrite the rules for selecting photovoltaic materials. The key guidelines from 1980 publications [20] are given in the following paragraphs.

When one considers the availability of materials at reasonable cost, one has to establish the rate of production required for the application and compare it to the current world rate of production as well as to the possible total availability of the material in the earth's crust. As shown in Figure 1, a number of elements used in solar cell manufacturing have very low level of reserve [21]. In order that the use of the material in the photovoltaic application does not drive up the cost of the material, the additional uses for photovoltaic applications must be less than $10 \%$ of the world production (study of world production rates of minerals shows that historically the production rate of any mineral has rarely grown faster than $10 \%$ per year). For example, due to high demand of poly-silicon, price of poly-silicon

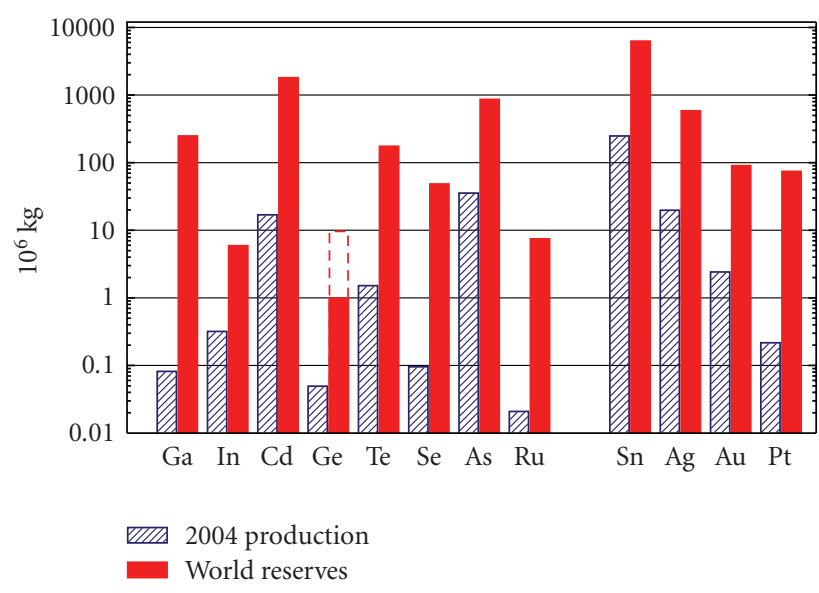

FIGURE 1: Estimated 2004 annual production levels and material reserves for various materials used in PV industry (from [21]).

went high in 2008 due to increased demand and poor supply. Fortunately, due to abundance of the raw material, the supply chain of poly-silicon has improved again. Recently, iSuppli has reported that due to an increase in production of polysilicon by $112 \%$ in 2009 , price will drop by half [22].

\subsection{Low Cost of Ownership (COO) for Manufacturing.} Similar to the semiconductor manufacturing and LCD manufacturing industry, photovoltaic manufacturing also needs huge capital investments. Ideally for a given technology, the capital expenditures should be as low as possible. However, capital expenditure is only one component in the cost of ownership. Since the manufacturing of a PV module consists of a number of processing steps, the underutilization of equipment adds extra cost. Over the life time of the manufacturing facility, the equipment reliability, utilization, and yield of the PV modules have a greater impact on cost of ownership than initial purchase cost. The cost of ownership can be expressed by following expression [23]:

$$
\mathrm{COO}=\frac{\mathrm{CF}+\mathrm{CV}+\mathrm{CY}}{\mathrm{TPT} * \mathrm{Y} * \mathrm{U}},
$$

where COO: cost of ownership, CF: fixed cost, CV: variable cost, CY: cost due to yield loss, TPT: throughput, Y: composite Yield, U: utilization.

The use of a roll-to-roll (RTR) process (similar to the way in which newspapers are printed) is a driving force to develop PV manufacturing processes with low capital expenditures. The success or failure of RTR and other similar processes depends on the yield of each process step and resulting PV module yield. The above expression can be used to judge the suitability or nonsuitability of a low-cost capital expenditure manufacturing process versus alternate highcost capital expenditure manufacturing.

In the selection of appropriate manufacturing process technology, process variability is one of the important issues. In other words the power out of each device in a module and the power output of each module in a system must be as 


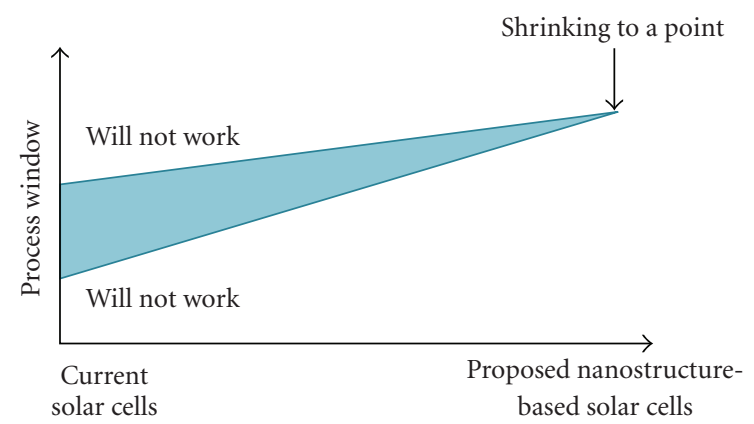

FIGURE 2: Shrinking process window for ultra-small structures.

identical as possible. Due to series and parallel connections (to get desired voltage and current) devices or modules with minimum voltage or current will dictate the power output of the system. A sophisticated and expensive advanced process control (APC) will provide lower cost of ownership than a low-cost statistical process control for a given process used in the PV module manufacturing. For one-dimensional nanostructure such as single-wall carbon nanotubes, we have demonstrated the need for a high level of control of the process variation which is far beyond that which is currently achievable through conventional methods [24]. Process variability is one of the most critical issues for nanostructurebased integrated circuit manufacturing. The same issues are also true for solar cells based on nanostructures. As shown in Figure 2, for nanostructures-based solar cells the process window is replaced by the process points. Relative to currently manufactured solar cells, the COO will be higher for nanostructure-based solar cells.

2.3. Low Production Cost. For reducing the production cost of PV modules, it is necessary to use larger silicon wafers or larger substrates rather than the smaller ones. For product cost reduction, this technique has been very successful for IC and display industry. Other than the efficiency of PV modules, energy consumed in the manufacturing process, materials, gases and substrates cost, automation and throughput, yield is a very important factor in the overall cost. Of course factors such as low labor cost and low cost of electricity also affect the cost of PV modules. The typical manufacturing cost relationship should be used to size the appropriate production capacity of the manufacturing process. An absolute control on the supply chain and ultra-large-scale volume manufacturing are the principal requirements to bring PV technology to a level where generation of electricity is cheaper than other energy sources.

2.4. Prospects for Further Cost Reduction. Other than increasing the efficiency of $\mathrm{PV}$ module, the manufacturing process should be capable of further cost reduction. For cost reduction of the PV modules, the change of substrate size with time by the IC and display industry is the perfect choice for PV industry. Currently some amorphous silicon manufacturers are using glass substrates of the size of $5.7 \mathrm{~m}^{2}$.
Similar to LCD industry these manufacturers can increase the glass size to Gen 10 substrates with the area equal to $8.7 \mathrm{~m}^{2}$. Without inventing any new process, the Gen 10 substrate size will provide cost reductions similar to LCD industry.

2.5. Environmental Safety and Health (ESH) Issues and Green Manufacturing. As compared to other method of electricity generation, PV technologies have distinct environmental advantages for generating electricity over conventional technologies. Electricity generation by PV systems does not produce any noise, toxic-gas emissions, or greenhouse gases. Photovoltaic energy not only can help meet the growing worldwide demand for electricity, but it can do so economically without any environmental concerns. Compared to burning coal, every gigawatt-hour of electricity generated by photovoltaics would prevent the emission of about 10 tons of sulfur dioxide, 4 tons of nitrogen oxides, 0.7 tons of particulates, and up to 1000 tons of carbon dioxide.

The techniques used in PV manufacturing are quite similar to $\$ 350$ billion semiconductor industry. During the last half century the semiconductor industry has evolved to the point that in spite of the use of a number hazardous chemicals, tools and processes exist for the safe handling of such chemicals, materials, and gases. The PV industry has adopted handling of materials chemicals, and gases in a way similar to the semiconductor industry. Thus from environmental, occupational health, and safety point, there is no concern. The only material that poses a real concern is the use of Cadmium $(\mathrm{Cd})$ in CdTe-based solar cells. According to the Occupational Safety and Health Administration (OSHA) of USA, Cadmium is considered both toxic and a lung carcinogen. OSHA considers all Cd compounds (including $\mathrm{CdTe}$ ) to be toxic. For further reading of health problems related to the use of $\mathrm{Cd}$ in solar cells interested reader is referred to our earlier publication [3].

\section{Critical Examination of Proposed Nanostruc- tures for Solar Cell Applications}

The nanostructures involve length scale of approximately $1-$ $100 \mathrm{~nm}$ range. In this paper we will not differentiate between the approaches used in the fabrication of these structures. The issue of "bottom up" (atom-by-atom approach to build the required $<100 \mathrm{~nm}$ dimension) or "top down" (current lithography techniques used to reduce material dimension $<100 \mathrm{~nm}$ ) approach will be dictated by throughput and cost related manufacturing issues. It has been known for long time that the properties of ultra-thin films differ from the bulk values. The invention of scanning tunneling microscope in 1981 and the advancements in the silicon integrated circuits as well as other related semiconductor products (e.g., improved detectors with high signal-to-noise ratio) have helped the development of instruments that have the ability to manipulate and analyze material on the atomic scale. Research in the nanodimension material in the last decade has established that the properties of nano-dimension material differ from the corresponding thin film materials. 


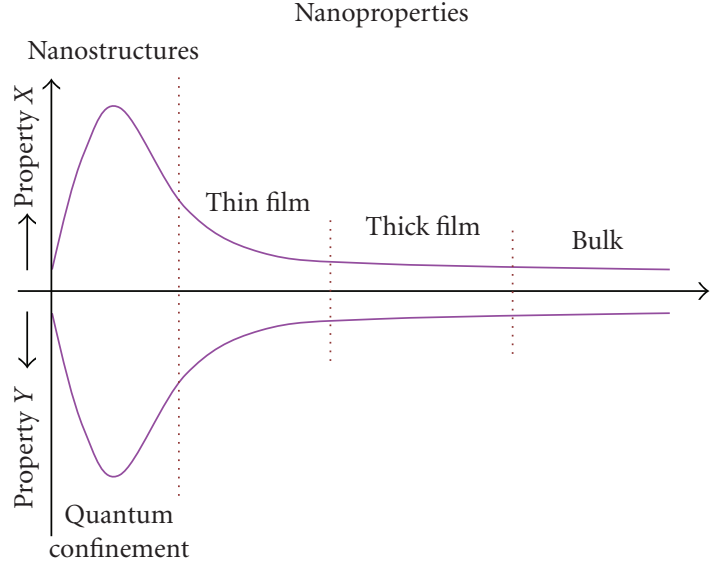

FIgURe 3: Change in properties of any material due to its physical size.

TABle 1: Various solar energy losses in single junction silicon (1.1 eV energy band gap) solar cell under AM 1.5 solar spectra at $300^{\circ} \mathrm{K}$ temperature [13].

\begin{tabular}{lc}
\hline Photo-electro energy conversion & $32.9 \%$ \\
\hline Unabsorbed energy losses & $18.7 \%$ \\
Heat loss & $46.8 \%$ \\
Other losses & $1.6 \%$ \\
\hline
\end{tabular}

As shown in Figure 3, at nanoscales the properties of material depend on the quantum confinements. The one-to threedimensional nanomaterials provide unique opportunities to optimize a number of physical, chemical, biological, mechanical, electrical, optical, and thermal properties of interest for future photovoltaic devices. The challenge is to integrate these unique properties of nanostructures and enhance the performance, reliability, and yield of photovoltaic devices for manufacturing next generation of photovoltaic modules.

In 1961, Shockley and Queisser calculated thermodynamic limit of maximum efficiency for a $\mathrm{p}$-n junction silicon ( $1.1 \mathrm{eV}$ energy bandgap) solar cell to be around $33 \%$ under AM 1.5 solar illumination at $300^{\circ} \mathrm{K}$ [25]. The energy associated with photons greater than the energy band gap of silicon is converted into heat. As shown in Table 1, heat loss is mainly responsible for lower efficiency of silicon solar cells. The unabsorbed energy loss can be partially recovered by using the concept of tandem solar cells where higher and lower energy band gap solar cells are connected optically in series. The concept of tandem solar cells is already used for manufacturing amorphous silicon solar cells and III-V-based high efficiency concentrator solar cells. Since a major part of the incident solar energy is lost as heat, maximum efforts have been made to prevent incident solar energy getting converted to heat. These losses are the driving force to build new approaches to utilize the energy losses. As mentioned earlier, structures of size $1 \mathrm{~nm}$ to $100 \mathrm{~nm}$ are proposed to make solar cells more efficient. The use of nanostructures has been suggested to build new highly efficient solar cells considering the following key points. (1) Hot carriers generated by absorbing photons of energy more than the energy band gap can be employed to generate additional current and or voltage, and (2) energy states in the energy band gap can be used to trap carriers generated from photon of energy lower than the energy band gap. Various approaches based on the one-, two-, and three-dimensional nanostructures (quantum dots and semiconductor nanocrystals) are currently being pursued to utilize the energy losses listed in Table 1. In the following subsections, we have examined the theoretical and experimental results of various nanostructures reported in the open literature.

3.1. Proposed Use of Hot Carriers to Boost up Solar Cell Efficiency. There have been numerous publications discussing the potential use of hot carriers for solar cell efficiency enhancement $[6,9,10,12,26-31]$. Hot carrier solar cells claim to convert excess photon energies into stable form before the excited states equilibrate with the environment. In semiconductors, excess energy appears as the kinetic energy of the carriers where as in molecules it becomes a phonon and is dissipated as heat. As shown in Figures 4(a)-4(b), when the incoming photon has excess energy $(h \nu)>E_{g}$, electrons are excited and the thermalization occurs through carrierphonon scattering. Excess energy is delivered to the carriers of lesser effective mass. Thus for the highest efficiency of the solar cell, excess photon energies must be delivered to the bands capable of sustaining the hot carriers. The following are the proposed ways for extraction of the excess energy.

(1) Remove the carrier from the device before it cools and obtain a higher energy electron and thus getting a higher output voltage (Figures $4(\mathrm{c})-4(\mathrm{~d})$ ). Theoretically for this to be feasible, the rate of cooling of hot electrons must be lower than the rate of hot carrier separation, transport, and collection at contacts [30].

(2) Make the excited "hot" electron spend its extra energy to excite another electron from valence band and thus getting a higher output current (Figures 4(e)-4(f)). This is known as impact ionization and can occur only if the rate of impact ionization is more than the relaxation processes which include generation of phonon and Auger recombination. [30].

The photocurrent generation in semiconductor $\mathrm{p}$-n junction of solar cell is shown in Figure 5. When a photon with energy more than band gap of absorber material hits $\mathrm{p}-\mathrm{n}$ junction, it creates an electron hole pair and due to the inbuilt electric field, photoproduced carriers are transported to the electrodes. Thus for making a solar cell, the basic requirements are an absorber material and a junction with electric field that assists transport of the photogenerated carriers to the electrodes. There is also a probability that photogenerated carriers can recombine before reaching the electrodes. Therefore for crystalline and polycrystalline solar cells, the charge separation time of photo generated carriers must be smaller than the minority carrier lifetime.

For the bulk materials, rate of impact ionization or multiple carrier excitations (MCEs) is slower than the rate of 


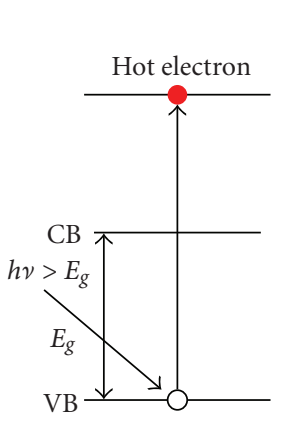

(a)

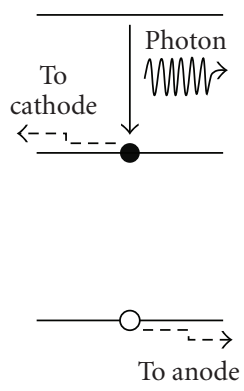

(b)

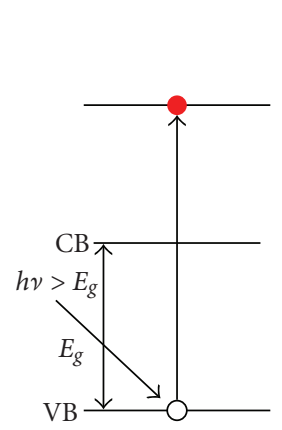

(c)

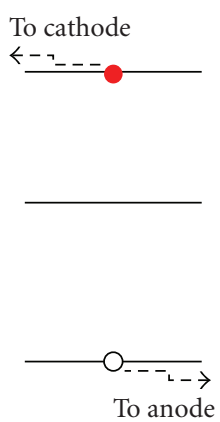

(d)

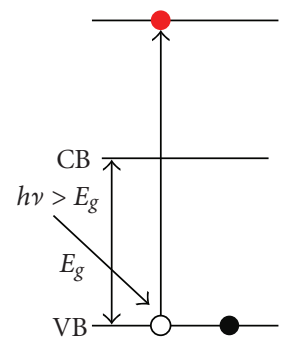

(e)

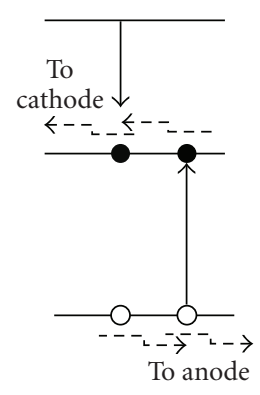

(f)

FIgURe 4: (a) A photon with energy $(h \nu)$ greater than band gap energy $\left(E_{g}\right)$ strikes on solar cell and excites an electron to Conduction Band (CB) from Valence Band (VB); (b) the extra energy $\left(h \nu-E_{g}\right)$ is released as phonon; (c) a photon with energy $(h \nu)$ greater than band gap energy $\left(E_{g}\right)$ strikes on solar cell and excites an electron to CB from VB; $(\mathrm{d})$ the extra energy $\left(h \nu-E_{g}\right)$ is used to produce higher voltage by $h \nu-E_{g}$; (e) a photon with energy $(h \nu)$ more than band gap energy $\left(E_{g}\right)$ strikes on solar cell and excites an electron; (f) extra energy $\left(h \nu-E_{g}\right)$ is used to excites one more electron from VB to CB.

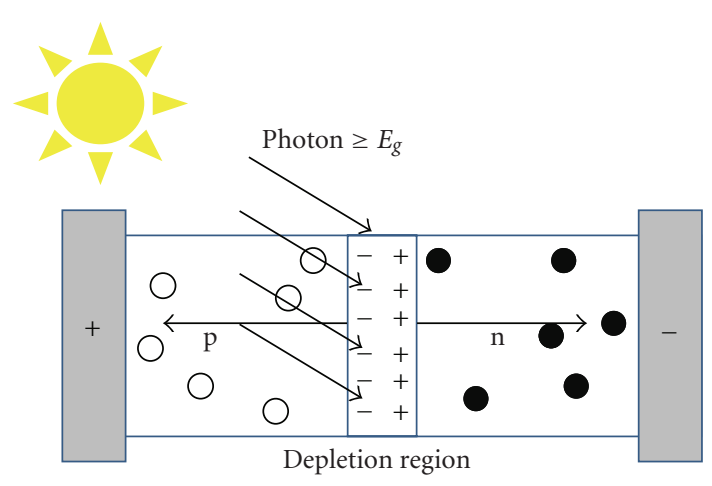

FIGURE 5: Basic p-n junction solar cell and charge transport phenomena.

thermal cooling of hot carriers through intraband relaxations processes [9]. Therefore various groups started to investigate the use of quantum dots for utilizing hot carrier effects [9, $29,32]$. However, to date no one has provided experimental data to prove that for quantum dots the rate of multiple carrier excitation is faster than the thermal cooling rate of hot carriers. Also, the Auger recombination rate and cooling rate depend on the surface area of the nanostructure as shown in Figure 6 [13]; for example, the Auger recombination is more in nanorods than nanodots [9]. Results shown in Figure 7 indicate that not only carrier relaxation time decreases, photo generated exciton life time also decreases with the size of nanocrystal [13].

In [32], authors have reported excitation of seven electrons from a photon in PbSe nanocrystal and have reported an internal quantum efficiency of $700 \%$. Based on the type of measurements reported in [32], one is tempted to believe that for solar cells more than one EHP could be generated for each incoming photon, which in turn will improve the solar cell efficiency. In reality, for solar cell efficiency enhancement these multiple EHPs must be extracted from the device through electrodes. Fundamentally this is not possible, since all the reported internal quantum

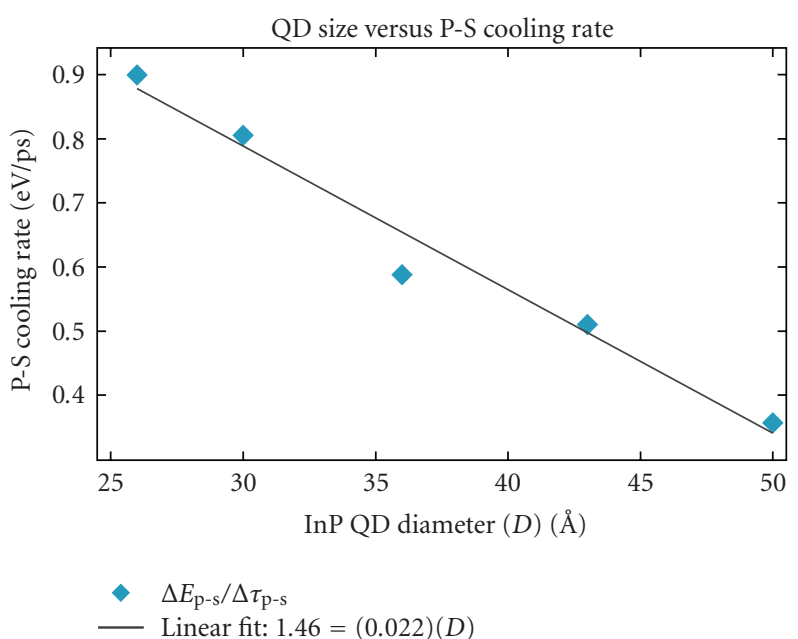

FIGURE 6: Carrier cooling rate increases as size of quantum dot decreases (from [13]).

efficiencies of above $100 \%$ are based on the measurement of Transient Absorption Spectra (TAS). In TAS, two ultrafast femtosecond LASER pulses are used. First, the high energy LASER beam is used to excite the electrons and the other LASER beam probes the excited states. The pumped power used for multiple exciton generation in [6] is $1.126 \mathrm{~mW} / \mathrm{cm}^{2}$ which is roughly an order of magnitude more than the power available at $600 \mathrm{~nm}$ in AM1.5 solar spectrum. The TAS measurements may give information about the excited states [28], but these experimental conditions have nothing to do with the required conditions for solar cell applications.

As early as 1980 one of us [33] provided experimental data to refute the claim that one can observe short circuit current density greater than predicted by Shockley and Queisser limit [25]. An extensive search of the open literature beyond 1980 did not show any direct current-voltage measurements under illumination or enhancement in efficiency of solar cells by utilizing hot carriers or by any other mechanism including generation of multiple excitons. 


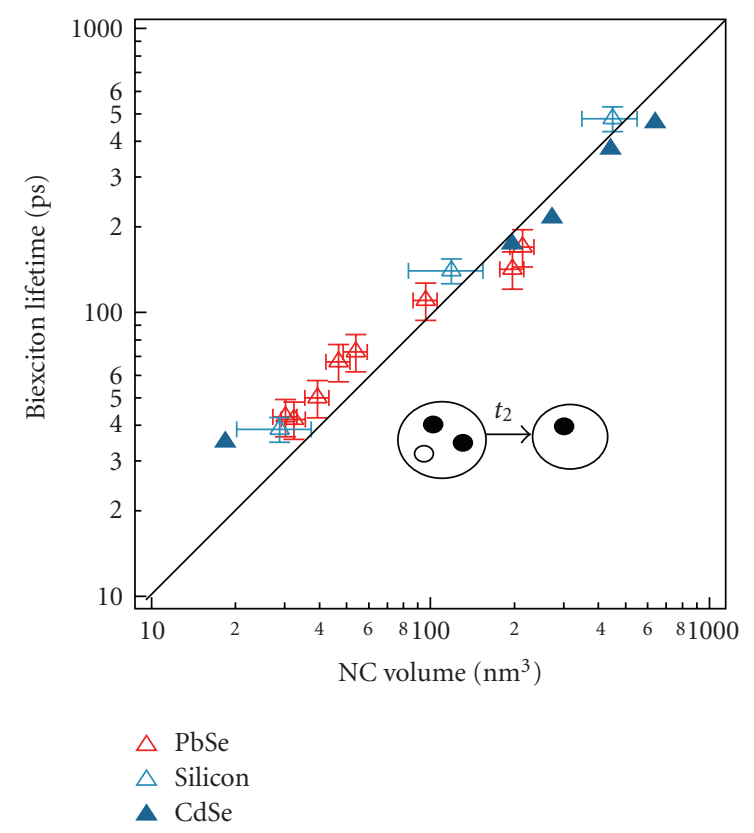

FIGURE 7: Biexction lifetime as a function of volume of nanocrystal (from [13]).

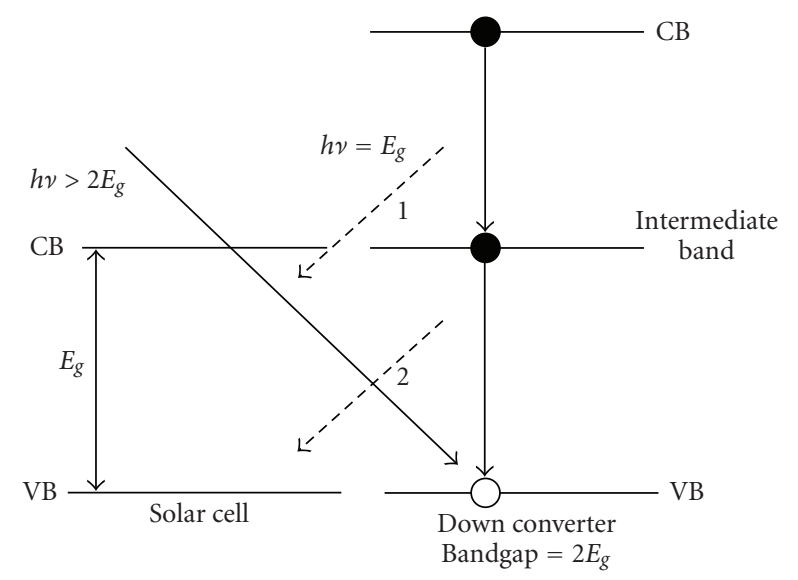

Figure 8: A photon with energy more than $2 E_{g}$ strikes on down converter and produces two photons with energy $E_{g}$.

3.2. Up Conversion and Down Conversion. Up/Down conversion involves altering the incident spectrum which is available to the solar cell. In down conversion, one high energy photon will be split in to two or more photons which can be converted into two or more electron hole pairs by the solar cell. In up conversion, two or more low energy photons are converted in to a single photon which can be converted by the solar cell to generate an electron hole pair.

Figure 8 shows the operating mechanism of proposed down converter solar cell. The solar cell is a regular siliconbased solar cell with energy band gap of $E_{g}$. It converts only photons of energy greater than $E_{g}$ in to EHPs. According to proposed down conversion mechanism, if a photon with energy of $2 E_{g}$ strikes the solar cell and passes through it and further strikes the converter placed behind the solar cell which has an energy band gap of $2 E_{g}$. This results in exciting an electron from the valence band to the conduction band. This excited electron falls back into the valence band in two steps. In the first step, it falls to an intermediate state emitting a photon "1" of energy $E_{g}$ and then in the second step, it falls down in to the valence band emitting another photon " 2 " as shown in Figure 8 of energy $E_{g}$. These two photons with energy $E_{g}$ will go back to the solar cell and get converted in to two EHPs. Thus, the single high energy photon will result in two EHPs which is not possible in a conventional solar cell. Also, the solar cell is assumed to be very thin to pass photon with energy $2 E_{g}$ which could have a negative impact on the efficiency.

The theory of high efficiency down conversion process is proposed on the assumption that "no nonradiative recombination takes place anywhere in the device" [34]. For a photon of energy greater than $2 E_{g}$, a band-toband transition happens in the converter and these excited electrons recombine via intermediate bands in the converter. All the photons with energy between $E_{g}$ and $2 E_{g}$ will be wasted if they cross the solar cell. Also, photons with energy more than $2 E_{g}$ will be absorbed by the converter and will result in thermalization which will further decrease the efficiency. If the down converter is placed above the solar cell, it will absorb all photons with energy greater than its band gap. Thus, the solar cell collects photons only generated by the down converter via photoluminescence. Also, only half of the photons can be expected to be radiated into the solar cell. The other half will be radiated outwards from the convertor.

With the assumptions described above, the AM 1.5 efficiency limit for a down-conversion solar cell with $E_{g}$ $=1.05 \mathrm{eV}$ is $39.6 \%$ [34] while the Shockley and Queisser limit is about $33 \%$ for single junction silicon solar cell [25]. The mathematical calculations about up conversion also have fundamental flaws and the efficiency limit for this process is calculated as $47.6 \%$ for nonconcentrated sunlight [35]. The authors of [36] have conducted a review on the existing materials to modify the solar spectrum and a few results on solar cell up/down conversion using nanostructures were also reported. Most of the results reported in [36] are nothing other than the explorations of the photoluminescence properties of materials.

Use of Si nanocrystals (NCs) as a down converter is reported in [37] which show no change in open circuit voltage and a little increase in short circuit current which results in net efficiency increase by only $0.4 \%$. Also, it is worth mentioning here that in [37] the results of only one sample were reported for claiming the efficiency improvements. As reported in [37], the difference between the value of current density measured by spectral response and the value extracted from electrical measurement data is $40 \%$. Thus the legitimacy of the claim by authors of [37] about the $0.4 \%$ net efficiency improvement by the use the down converter based on silicon nanocrystals is questionable. The internal quantum efficiency results reported in [37] are shown in Figure 9. The reduction in internal quantum efficiency for cells annealed at $200^{\circ} \mathrm{C}$ and $500^{\circ} \mathrm{C}$ indicates device reliability problems. [37] was published in 2004 and in the last five years 


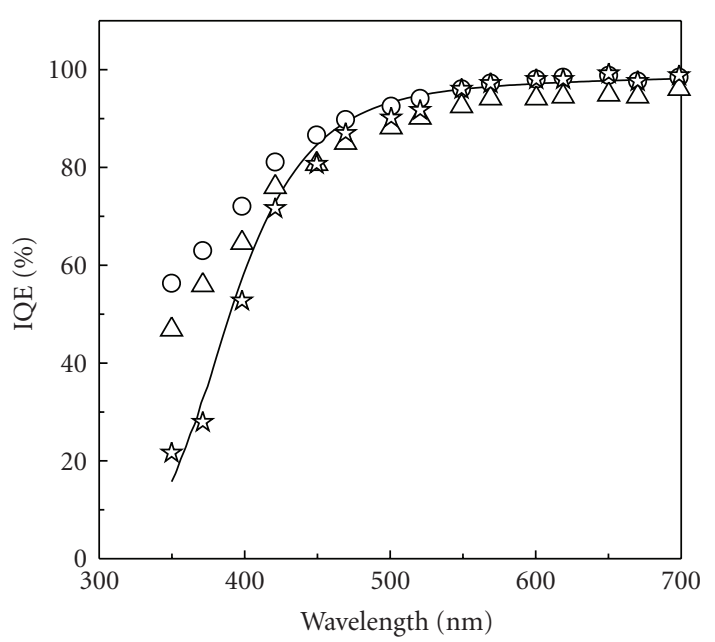

Silica layer containing silicon nanostructures annealed at

$$
\begin{aligned}
& \text { ○ } 30^{\circ} \mathrm{C} \quad \text { Silica layer without } \\
& \triangle 200^{\circ} \mathrm{C} \quad \text { silicon nanostructures } \\
& \text { 公 } 500^{\circ} \mathrm{C}
\end{aligned}
$$

FIgure 9: Measured internal quantum efficiency of solar cell with (symbols) and without a silica layer containing silicon nanocrystals. The reduction in internal quantum efficiency for cells annealed at $200^{\circ} \mathrm{C}$ and $500^{\circ} \mathrm{C}$ indicates reliability problem (from [36]).

no new results about improving the efficiency by up/down conversion have been reported.

In summary, no one has reported experimental results of the up/down conversion process with a meaningful efficiency enhancement to pursue these nanostructure-based solar cells for further research and development.

3.3. Nanocrystals-Based Tandem Solar Cells. As we stated earlier, the full solar spectrum cannot be efficiently absorbed by a solar cell using single energy band gap material. In 1955 for the first time, Jackson proposed to use layers of different energy band gap materials to enhance the solar cell efficiency [38]. III-V semiconductor and amorphous silicon-based tandem solar cells are already in production. A lot of research has been done in the search for a perfect combination of materials to absorb the entire solar spectrum. This motivated researchers to think for the application of low-dimensional structures such as quantum wells as an absorber layer in solar cells. The use of quantum wells in solar cells was first proposed by Burnham and Duggan in 1990 [39]. It is well-known fact that the energy band gap of quantum confined structures can be tuned by altering their size.

Very recently Cho et al. [40] have shown an efficiency of $10.6 \%$ by embedding $3 \mathrm{~nm}$ quantum dots in $2 \mathrm{~nm} \mathrm{SiO}_{2}$ layers. They used 15 layers of the phosphorous doped quantum dots embedded in $\mathrm{SiO}_{2}$ on a $\mathrm{p}$ type crystalline silicon wafer. Also, they claimed that the current density of this cell is $29.8 \mathrm{~mA} \mathrm{~cm}^{-2}$ and it is equivalent to the current density of single junction nontextured solar cell [40]. Table 2 summarizes their experimental results. It can be seen from

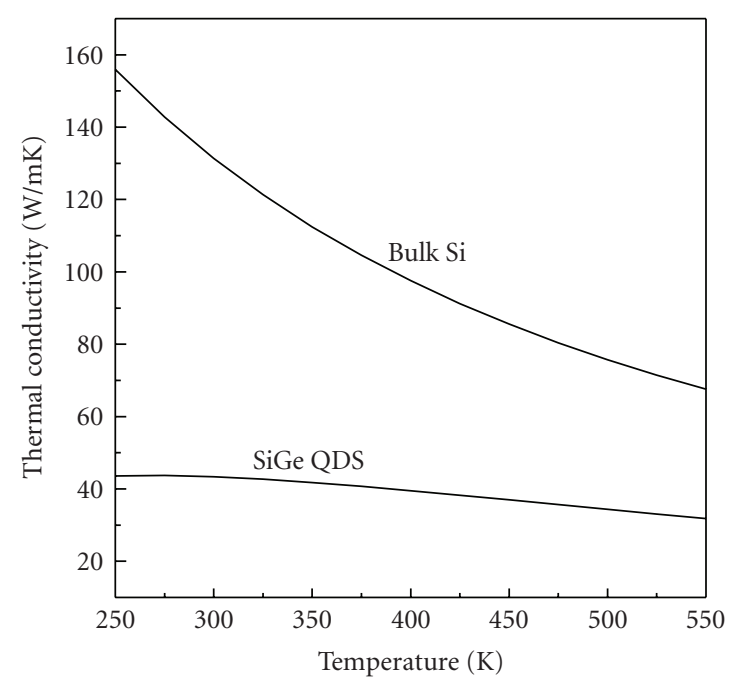

FIGURE 10: In plane lattice thermal conductivity of $\mathrm{Si}_{1-\delta} \mathrm{Ge}_{\delta}$ quantum dot superlattice and bulk silicon as a function of temperature. The value of $x$ is 0.05 and size of quantum dot is $4 \mathrm{~nm}$ (from [43]).

Table 2 that there is not any significant difference in the efficiency of various sized quantum dots embedded in the oxide layers. However, the maximum reported efficiency from their work is far below the efficiency of commercially available single junction silicon solar cells. In case of quantum dots as well as other nanostructures-based semiconductor devices fundamental issues related to heat removal and reliability are very important [24]. Therefore thermal conductivity of quantum dots [41-44] must be considered for applications of quantum dots in solar cells. As shown in Figure 10 [43], the thermal conductivity of the $\mathrm{Si}_{1-\delta} \mathrm{Ge}_{\delta}$ quantum dot super lattice is much lower than that of bulk silicon. The scattering of acoustic phonons on quantum dots is key scattering mechanism for decrease in the thermal conductivity [43]. Figure 11 shows the in-plane lattice thermal conductivity as a function of dot volume fraction $(\delta)$ of Germanium in $\mathrm{Si}_{1-\delta} \mathrm{Ge}_{\delta}$ alloy with dot size as the variable parameter. Additional complexity in the applications of quantum dots in solar cells will arise from the fact that quantum dots in the order of quadrillion $\left(10^{15}\right)$ will be required for a silicon wafer of the size of $150 \mathrm{~mm}$. Physics related to many body problems must be considered to understand the interactions among various quantum nanocrystals [45]. Control on the size distribution of nanocrystals is another challenge. The interaction between nanocrystals increases when size distribution of nanocrystals is large and results in reduced mobility and short circuit current. The reason for the mobility reduction is hopping of charge carriers between adjacent nanocrystals [17].

3.4. Intermediate Band Solar Cells (IBSCs). In 1960 Wolf described various loss factors in solar cells and discussed various mechanisms including multitransition solar cells (introducing energy levels in forbidden energy gap of active layer) to reduce energy losses [46]. Luque and Marti [47] introduced the concept of intermediate band solar cells in 
TABLE 2: Electrical measurements of solar cell with different size silicon nanocrystals embedded in layers of silicon rich oxide (SRO)/Silicon Dioxide $\left(\mathrm{SiO}_{2}\right)$ under standard condition (AM 1.5 spectrum, $100 \mathrm{~mW} \mathrm{~cm}^{-2}, 298^{\circ} \mathrm{K}$ ) (from [40]).

\begin{tabular}{|c|c|c|c|c|}
\hline $\begin{array}{l}\mathrm{SRO} / \mathrm{SiO}_{2} \\
\text { thickness, } \\
\text { number of bilayers }\end{array}$ & $\begin{array}{c}\text { Open circuit } \\
\text { voltage } V_{\mathrm{oc}}(\mathrm{mV})\end{array}$ & $\begin{array}{l}\text { Short circuit } \\
\text { current density } \\
J_{s c}\left(\mathrm{~mA} \mathrm{~cm}^{-2}\right)\end{array}$ & Fill factor(\%) & Efficiency (\%) \\
\hline $3 \mathrm{~nm} / 2 \mathrm{~nm} 15 \mathrm{BL}$ & 555.6 & 29.8 & 63.8 & 10.6 \\
\hline $4 \mathrm{~nm} / 2 \mathrm{~nm} 25 \mathrm{BL}$ & 540.3 & 25.0 & 76.8 & 10.4 \\
\hline $5 \mathrm{~nm} / 2 \mathrm{~nm} 25 \mathrm{BL}$ & 517.9 & 27.9 & 72.3 & 10.5 \\
\hline $8 \mathrm{~nm} / 1 \mathrm{~nm} 25 \mathrm{BL}$ & 470.8 & 18.6 & 65.1 & 5.7 \\
\hline
\end{tabular}

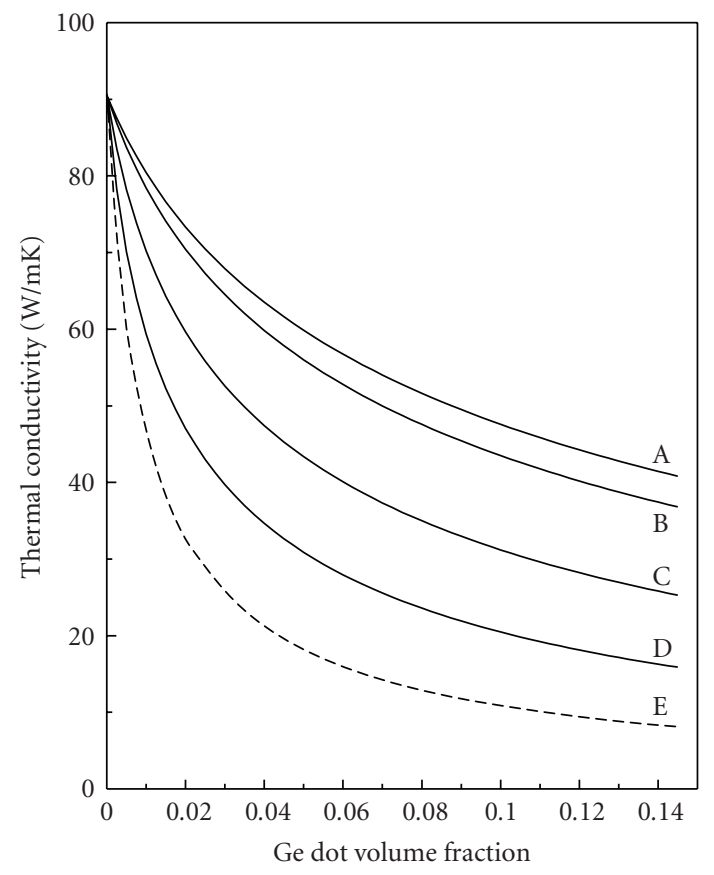

$\begin{array}{ll}\text { Dot radius } & \\ \text { A } 10 \mathrm{~nm} & \text { D } 2 \mathrm{~nm} \\ \text { B } 8 \mathrm{~nm} & \text { E } \text { Mass-difference limit } \\ \text { C } 4 \mathrm{~nm} & \end{array}$

FIGURE 11: In-plane lattice thermal conductivity as a function of dot volume fraction $(\delta)$ of Germanium in $\mathrm{Si}_{1-\delta} \mathrm{Ge}_{\delta}$ alloy. The value of dot size is $10.0 \mathrm{~nm}, 8.0 \mathrm{~nm}, 4.0 \mathrm{~nm}$, and $2.0 \mathrm{~nm}$ for curve $A, B, C$, and $\mathrm{D}$, respectively (from [43]).

1997 which is similar to the concept of multitransition solar cells. The basic concept of IBSC is to have an intermediate band to utilize low energy photons from the solar spectrum [47]. The formation of intermediate band is proposed by utilizing some impurities other than basic absorber material or alloy or quantum dots [48-50]. Fundamentally, the concept of IBSC is against the theory of recombination generation where energy levels near the mid-gap degrade the performance of all type of solar cells. This is indeed the case as has been confirmed by the experimental results [48]. The dark and light current density-voltage characteristics of GaAs reference cell, GaAs IBSC solar cells based on quantum dot with and without delta $(\delta)$ doping of quantum dot layers are shown in Figures 12 and 13, respectively. As expected the results of Figures 12 and 13 confirm that the introduction of

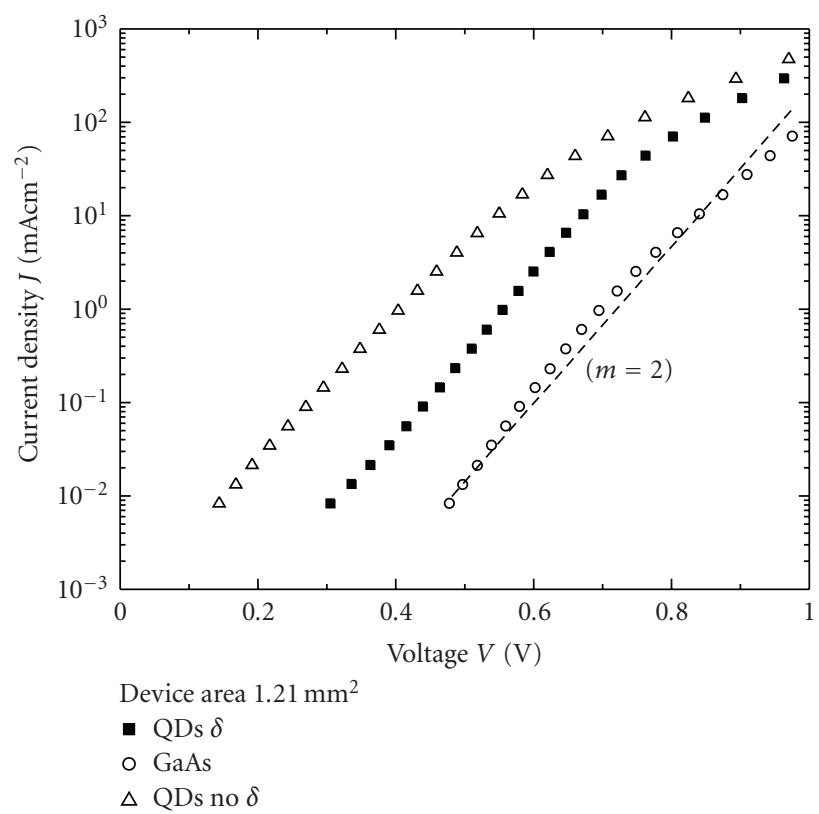

FIgURE 12: The dark current density-voltage characteristics of GaAs reference cell, GaAs IBSC solar cells based on quantum dot with and without delta $(\delta)$ doping of quantum dot layers (from [48]).

intermediate band layer degrades the solar cells performance. Similar negative results about IBSC solar cells results have been reported by others [51].

3.5. Dye-Sensitized Solar Cells. Dye-sensitized solar cells (DSCs) are currently being explored as ultra-low-cost solar cells. DSCs utilize three main components to perform photoelectro conversion which are metal oxide semiconductor nanostructures, dye, and electrolyte. A dye is used to create electron hole pairs and other two materials transport theses photogenerated charge carriers to the electrodes. The most popular metal oxide semiconductor nanostructures are made of Titania $\left(\mathrm{TiO}_{2}\right)$. Various researchers have proposed the use of nanotubes for DSCs and these results are discussed in the next paragraph. For a device of aperture area equal to $0.219 \mathrm{~cm}^{2}$ and platinum coated glass as the counter electrode, the best efficiency reported by researcher at Sharp for DSC is $11.18 \%$ [52]. Scaling to large area practical solar cells is a difficult challenge. A number of dyes including Ruthenium-based diketonato $\mathrm{Ru}$ (II) complex are used in 


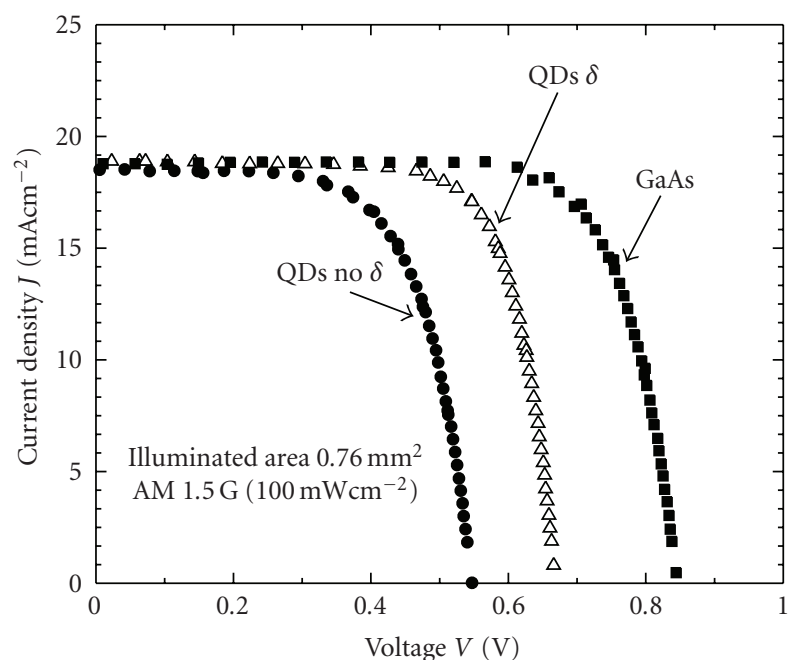

FIGURE 13: The light current density-voltage characteristics of GaAs reference cell, GaAs IBSC solar cells based on quantum dot with and without delta $(\delta)$ doping of quantum dot layers (from [48]).

DSCs. Ruthenium is a very costly metal and it requires extra recycling fee [11]. The hole transport material in DSCs, that is, electrolyte, can be a room temperature ionic liquid, quasisolid state, or solid state material [11]. A liquid electrolyte can fill the pores of the metal oxide semiconductor nanoparticles but it is not possible with a quasi-solid state or solid state electrolyte [18]. As a result, the best efficiencies are achieved for DSCs with liquid electrolyte. The liquid electrolytes get evaporated under exposure of solar radiations for longtime and poses fundamental problem of reliability.

Other than nanoparticles, nanowire (NW) film that provides a large surface area for the incorporation of light harvesting molecules, is being investigated to improve the performance of DSCs. However, NW DSCs rely on traplimited diffusion for electron transport, a slow mechanism that limits the device efficiency, especially at longer wavelengths. During operation, photons intercepted by the dye monolayer create excitons that are rapidly split at the NW surface, with electrons injected into the NW film and holes leaving the opposite side of the device by means of redox species in a liquid or solid-state electrolyte [53].

Another option for improving the absorption of red and near-infrared light is thickening the nanoparticle film to increase its optical density, which was unsuccessful because the film thickness comes to exceed the electron diffusion length through the nanoparticle network. Even incorporation of NW does not improve the efficiency. Solar cells constructed with $\mathrm{ZnO} \mathrm{NW}$ arrays of various surface areas, at one full Sun intensity, have highest $J_{\mathrm{sc}}=5.3-5.85 \mathrm{~mA} \mathrm{~cm}^{-2}$, $V_{\text {oc }}=0.61-0.71 \mathrm{~V}, F F=0.36-0.38$, and efficiency $\eta=1.2-$ $1.5 \%$ [55]. Incorporation of NW (Figure 14) into the film halves the fill factors, limiting their potential efficiencies. Ideally, $20 \mu \mathrm{m}$ long NW with a dominating diameter of $60 \mathrm{~nm}$, a density of $10^{10} \mathrm{~cm}^{-2}$, and surface area of $1080 \mathrm{~cm}^{2}$ per unit area of the substrate are needed where as the best that can be achieved is only $10 \%$ of ideal density and $18 \%$ of ideal surface area [54]. An effort to reduce the recombination rates through the use of core-sheath NW reduces the efficiencies to a maximum of $0.29 \%$ [56]. Titania shells $10-25 \mathrm{~nm}$ in thickness cause an increase in $\mathrm{V}_{\mathrm{OC}}$ and fill factor but only with a current fall off, resulting in a overall conversion efficiency, only up to $2.25 \%$ under $100 \mathrm{~mW} \mathrm{~cm}^{-2} \mathrm{AM} 1.5$ simulated sunlight [57]. Raising the efficiency of NW DSCs above $2.5 \%$ depends on achieving higher dye loadings through an increase in NW array surface area, which is a non trivial challenge. Besides the lower efficiencies of these NW cells, we note that increasing the aspect ratio of the NW and achieving 90\% higher densities are a daunting task.

In summary, the reliability of DSC is a fundamental problem. In addition to reliability, a number of manufacturing issues that relate to scaling, materials, defect density, and cost of ownership need to be addressed. Without solving these fundamental problems, DSC will not play any significant role in manufacturing of next generation of $\mathrm{PV}$ modules.

3.6. Organic Solar Cells. Organic solar cells are solution processed PV devices and are attractive due to low processing temperature and simple fabrication techniques. After nearly three decades, it is still a challenge for organic solar cells to enter in the commercial market. Poor electrical and structural properties and fast degradation under solar radiation are the fundamental problems for current organic solar cells. The major material problems with organic solar cells are charge generation, geminate recombination, electric and magnetic field effects on charge separation and recombination, carrier mobility, polaronic effects, charge collection efficiency, organic semiconductors with optical gap in the near IR spectral range to better match the solar energy spectrum, interpenetrating morphologies, exciton range, and its dependence on the film morphology [58].

To date, the best efficiency achieved for organic solar cells using a tandem cell structure for solar intensity of $20 \mathrm{~mW} \mathrm{~cm}^{-2}$ and $200 \mathrm{~mW} \mathrm{~cm} \mathrm{~cm}^{-2}$ is $6.7 \%$ and $6.1 \%$, respectively [59]. The device area was not mentioned in [59] and there may be a number of issues related to manufacturing of these devices. However, the fundamental problem is reliability. After 100 hours of continuous exposure under one sun (AM 1.5), the solar cell efficiency is degraded by $40 \%$ [59].

In 2001 one of us [60] critically examined the prospects of manufacturing organic semiconductor-based integrated circuits and pointed that there is no appropriate technology that can be implemented for pilot-line production, eventually leading to mass-scale manufacturing. Fundamentally, the low thermal conductivity of polymer semiconductor is a serious problem. Low-cost polymer deposition techniques (e.g., coating, electrodeposition, etc.) have not provided the desired microstructure properties. With the present approaches under investigation, it is difficult to imagine the possibility of controlling the surface defects and voids which are detrimental to the performance device performance [60]. Similar arguments apply to organic solar cells. As we mentioned in Section 2.2 the low-cost film deposition techniques (e.g., roll to roll process) are quite attractive from 


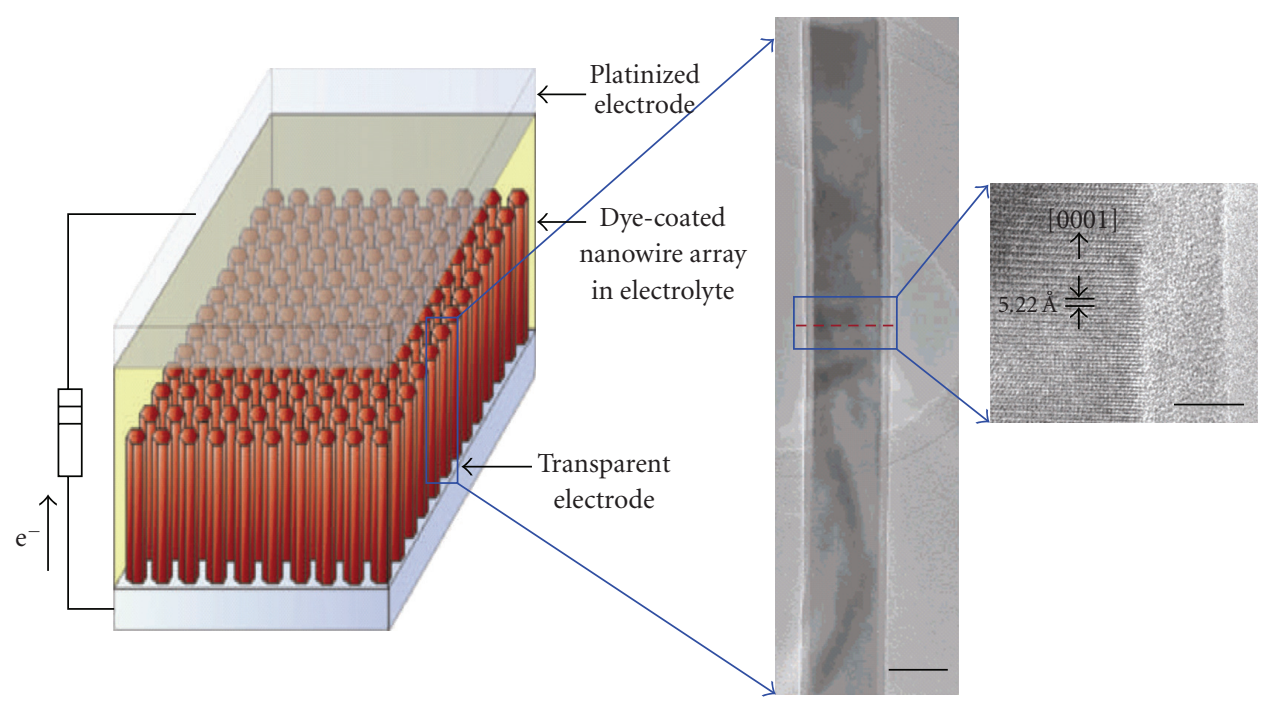

FIGURE 14: NW film-based DSC (from [54]).

capital expenditures. However due to high defect density, the cost of ownership of manufacturing for organic solar cells is high. Unless a new polymer is invented and manufacturing requirements discussed in Section 2 and reliability problems are solved, it is highly unlikely that organic solar cells will play any significant part in future manufacturing of photovoltaic modules.

\section{Discussions on Manufacturability of Nanostructure-Based Solar Cells}

Figure 15 shows the evolution of a new concept leading to the mass-scale manufacturing of a new product. In case of nanostructure-based solar cells, currently we are in the very first block of Figure 15. The physics related to nanostructures mostly deals with quantum phenomena. There is nothing wrong with quantum physics or the associated quantum phenomena. The problem lies in stretching the results of observed phenomena beyond what is evident from the observed results. As an example in August 2007 Beard et al. [6] published a paper on multiple exciton generation in colloidal silicon nanocrystals and claimed that their findings are of particular importance for Si dominated photovoltaic solar cell industry. Based on the results of [6], Bullis published in Technology Review [7] that by generating multiple electrons from high-energy photons, solar cells made of silicon nanocrystals could theoretically convert more than 40 percent of the energy in light into electrical power. As we have discussed in Section 3.1, there is no direct correlation between the photoluminescence results reported in [6] and the operation of solar cells. This type of hype exists both in technical journals as well as financial publications. Based on our in depth review of the literature we do not see any evidence that nanostructure-based solar cells will be part of PV module manufacturing. The lack of thorough understanding of the physical phenomena and the tendency of stretching observed experimental results is the fundamental reason that quantum phenomena-based nanostructures have a limited role to play in solar cells. Similar concerns about quantum phenomena-based nanostructures have been expressed for other semiconductor devices. According to Kelly [61], the new physics associated with one-dimensional and zero-dimensional structures, quantum interference, ballistic motion, or Coulomb blockade is unlikely to lead to practical devices until these effects can be exhibited, if ever they can, as robust phenomena.

Dye-sensitized solar cells (DSCs) and organic solar cells are currently being investigated by several companies. Other than manufacturing related issues, reliability is the main concern. It is worth mentioning here that the public and or private investment in a company does not mean that the investment will bring any product in the market and generate revenue. Due to lack of knowledge of manufacturing challenges, many times the investors think massscale manufacturing as a trivial exercise and the company is funded. Even for well-established companies, lack of necessary and sufficient data of defects, yield, and cost of ownership can result in failure. Based on the research work, Motorola formed a subsidiary called Thoughtbeam in November 2001 to develop, sell, and license its GaAson-silicon technology with applications to less-expensive optical communications, high-frequency radio devices, and high-speed microprocessor-based systems. Due to the fundamental nature of defects densities at the interface of GaAs and silicon and inability to deliver the desired device and circuit performance the subsidiary company was shut down in January 2003 [62]. Lack of manufacturing experience and not following the development and manufacturing cycle shown in Figure 15 can lead to wastage of millions of dollars. With an investment of at least $\$ 322$ million, Optisolar has to close operation due to manufacturing problems [63].

Based on the technical and business issues discussed in this section, it is obvious that none of the proposed 


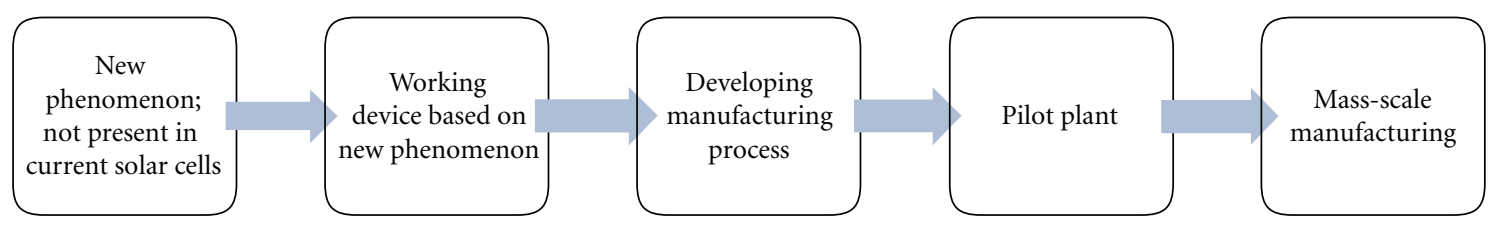

FIGURE 15: Basic product development and mass-scale manufacturing cycle.

nanostructure based solar cells that violates laws of physics, have any prospects of manufacturing PV modules. Due to the issues related to materials availability and toxicity of materials discussed in Section 2, CdTe, CuInGeSe2, and III-V semiconductor-based solar cells will not become a dominant player in multibillion dollar PV market. As one of us predicted in 1980 [20], silicon-based PV manufacturing will provide sustained growth of the PV industry and will emerge as a low-cost viable source of electricity generation for the 21st century. Following are the four silicon PV technology that are currently used in manufacturing, (i) ultra high efficiency single crystal technology, (ii) medium efficiency poly or multicrystalline technology, (iii) amorphous silicon thin film technology based on the use of larger glass substrates $\left(\sim 5.2 \mathrm{~m}^{2}\right)$, and (iv) amorphous silicon technology based on flexible substrates. From the low-cost and multiterawatt PV power generation point of view, only amorphous silicon solar cells based on the use of large glass substrates have the potential to reach the goal of providing installed PV system cost of $\$ 2.00 / w_{\mathrm{p}}$ in the next 3-4 years [64]. The ultra high efficiency single crystal PV modules may find a small niche market (where small area PV modules are warranted due to the area available for installation). The amorphous silicon technology based on flexible substrates may find a niche market for consumer products. The medium efficiency poly or multicrystalline silicon modules (limited size of silicon wafer) will not be able to be cost-effective compared to large area glass-based amorphous silicon thin film technology.

\section{Conclusion}

We have presented a comprehensive review on the subject of prospects of nanostructure-based solar cells for manufacturing future generation of photovoltaic modules. In search of reducing heat loss and utilizing the unabsorbed part of the spectrum, a number of solar cell concepts have been proposed. We have examined all proposed nanostructures for solar cell applications using the following five fundamental physics-based criterions.

(1) Interactions between charge carriers (electrons and holes) and phonon cannot be neglected.

(2) For all the known semiconductors, hot carriers (due to ultra short value of thermalization time) generated in one layer of the solar cell cannot be transported to the other side of the solar cell and collected at the other electrode.

(3) The phenomenon of photoluminescence has no direct relationship with solar cell operation.
(4) Intermediate band gap recombination center will reduce solar cell performance.

(5) For nanostructures, the thermal conductivity is lower than the bulk values. For practical applications of nanostructures, the material must have high thermal conductivity to transport heat from the device.

Most of the work reported in the literature is based on assumptions which are not realistic. Infinite carrier mobility, optimal absorption, and lossless contacts are some examples of unrealistic assumptions used in the work reported in the literature. With current knowledge base, it is highly unlikely that the nanostructure-based solar cells employing Hot Carriers, Up/Down conversion, and Intermediate Band Solar Cells will be used in the manufacturing of PV modules. Similar to the invention of phase shift masks (to beat the conventional diffraction limit of optical lithography); clever design concepts need to be invented to take advantage of quantum-based nanostructures.

Both dye-sensitized solar cells and organic solar cells have fundamental problem of reliability. Silicon-based PV manufacturing will continue to provide sustained growth of the PV industry and will emerge as a low-cost viable source of electricity generation for the 21 st century.

\section{Acknowledgments}

The authors would like to thank Elsevier, Wiley-VCH Verlag $\mathrm{GmbH} \& \mathrm{Co}$. KGaA, Institute of Physics and American Institute of Physics for granting us permission to republish some of the figures and tables used in this paper. The authors would also like to thank Dr. M. Green, Dr. M.C. Beard, Dr. A. Khitun, Dr. A. Freundlich, Dr. P. Yang, and Dr. A. Martí for their quick response for our e-mail requests.

\section{References}

[1] M. Osborne, "Worldwide photovoltaics installations grew $110 \%$ in 2008, says Solarbuzz," March 2009, http://www.pvtech.org/news/_a/worldwide_photovoltaics_installations_grew _stallations_grew_110_in_2008_says_solarbuzz.

[2] M. Osborne, "Gartner posts long-range forecast for photovoltaics industry," March 2009, http://www.pv-tech. org/news/_a/gartner_posts_long-range_forecast_for_photovol taics_industry.

[3] R. Singh, N. Gupta, and K. F. Poole, "Global energy conversion revolution in the 21 st century through solid state devices," in Proceedings of the 26th International Conference on Microelectronics (ICM '08), vol. 1, pp. 45-54, IEEE, Nis, Serbia, May 2008 . 
[4] G. Conibeer, M. Green, R. Corkish, et al., "Silicon nanostructures for third generation photovoltaic solar cells," Thin Solid Films, vol. 511-512, pp. 654-662, 2006.

[5] R. Singh, A. Venkateshan, K. F. Poole, D. Mohan, and P. Chatterjee, "Semiconductor manufacturing in the nanotechnology world of the 21st century," in Proceedings of the 25th International Conference on Microelectronics (ICM '06), pp. 2 8, Belgrade, Serbia, May 2006.

[6] M. C. Beard, K. P. Knutsen, P. Yu, et al., "Multiple exciton generation in colloidal silicon nanocrystals," Nano Letters, vol. 7, no. 8, pp. 2506-2512, 2007.

[7] K. Bullis, "Nanocrystals for Superefficient Solar Cells," Technology Review, March 2007, http://www.technologyreview. com/energy/19256.

[8] Department of Energy, Solar Energy Technologies Program, "Future Generation Photovoltaic Devices and Processes Selections," November 2007, http://www.docstoc. com/docs/942337/Future-Generation-Photovoltaic-Devicesand-Processes-Selections.

[9] V. I. Klimov, "Mechanisms for photogeneration and recombination of multiexcitons in semiconductor nanocrystals: implications for lasing and solar energy conversion," Journal of Physical Chemistry B, vol. 110, no. 34, pp. 16827-16845, 2006.

[10] A. Luque and A. Martí, "Ultra-high efficiency solar cells: the path for mass penetration of solar electricity," Electronics Letters, vol. 44, no. 16, pp. 943-945, 2008.

[11] L. M. Goncalves, V. Z. Bermudez, H. A. Ribeiro, and A. M. Mendes, "Dye-sensitized solar cells: a safe bet for the future," Energy and Environmental Science, vol. 1, pp. 655-667, 2008.

[12] A. J. Nozik, "Spectroscopy and hot electron relaxation dynamics in semiconductor quantum wells and quantum dots," Annual Review of Physical Chemistry, vol. 52, pp. 193-231, 2001.

[13] M. C. Beard and R. J. Ellingson, "Multiple exciton generation in semiconductor nanocrystals: toward efficient solar energy conversion," Laser and Photonics Reviews, vol. 2, no. 5, pp. 377-399, 2008.

[14] L. Tsakalakos, "Nanostructures for photovoltaics," Materials Science and Engineering R, vol. 62, no. 6, pp. 175-189, 2008.

[15] A. Luque, A. Martí, and A. J. Nozik, "Solar cells based on quantum dots: multiple exciton generation and intermediate bands," MRS Bulletin, vol. 32, no. 3, pp. 236-241, 2007.

[16] J.-F. Guillemoles and S. Kettemann, "Advanced concepts for photovoltaic conversion: bridging the gap from theory to real devices?" http://www.physnet.uni-hamburg. de/hp/kettemann/ispra.pdf.

[17] V. V. Kislyuk and O. P. Dimitriev, "Nanorods and nanotubes for solar cells," Journal of Nanoscience and Nanotechnology, vol. 8, no. 1, pp. 131-148, 2008.

[18] H. J. Snaith and L. Schmidt-Mende, "Advances in liquidelectrolyte and solid-state dye-sensitized solar cells," Advanced Materials, vol. 19, no. 20, pp. 3187-3200, 2007.

[19] R. Licklider, "The power of oil: the Arab oil weapon and the Netherlands, the United Kingdom, Canada, Japan, and the United States," International Studies Quarterly, vol. 32, no. 2, pp. 205-226, 1988.

[20] R. Singh and J. D. Leslie, "Economic requirements for new materials for solar photovoltaic cells," Solar Energy, vol. 24, no. 6, pp. 589-592, 1980.

[21] A. Feltrin and A. Freundlich, "Material considerations for terawatt level deployment of photovoltaics," Renewable Energy, vol. 33 , no. 2 , pp. 180-185, 2008.
[22] H. Wicht and S. deHaan, "Hann, Photovoltaics Raw Materials Tracker," 2008, http://www.isuppli.com/Abstract/ ABSTRACT\%20-\%20PV\%20Raw\%20Materials\%20Market\% 20Tracker\%202008.pdf.

[23] S. Y. Sohn and H. U. Moon, "Cost of ownership model for inspection of multiple quality attributes," IEEE Transactions on Semiconductor Manufacturing, vol. 16, no. 3, pp. 565-571, 2003.

[24] R. Singh, P. Chandran, M. Grujicic, et al., "Dominance of silicon CMOS based semiconductor manufacturing beyond international technology roadmap and for many more decades to come," in Semiconductor Fabtech, pp. 104-113, 30th edition, 2006.

[25] W. Shockley and H. J. Queisser, "Detailed balance limit of efficiency of p-n junction solar cells," Journal of Applied Physics, vol. 32, no. 3, pp. 510-519, 1961.

[26] P. Würfel, A. S. Brown, T. E. Humphrey, and M. A. Green, "Particle conservation in the hot-carrier solar cell," Progress in Photovoltaics: Research and Applications, vol. 13, no. 4, pp. 277-285, 2005.

[27] M. Wolf, R. Brendel, J. H. Werner, and H. J. Queisser, "Solar cell efficiency and carrier multiplication in $\mathrm{Si}_{1-x} \mathrm{Ge}_{x}$ alloys," Journal of Applied Physics, vol. 83, no. 8, pp. 4213-4221, 1998.

[28] Y. Takeda, T. Ito, R. Suzuki, T. Motohiro, S. Shrestha, and G. Conibeer, "Impact ionization and Auger recombination at high carrier temperature," Solar Energy Materials and Solar Cells, vol. 93, no. 6-7, pp. 797-802, 2009.

[29] A. J. Nozik, "Multiple exciton generation in semiconductor quantum dots," Chemical Physics Letters, vol. 457, no. 1-3, pp. $3-11,2008$.

[30] A. J. Nozik, "Quantum dot solar cells," Physica E, vol. 14, no. 1-2, pp. 115-120, 2002.

[31] M. C. Hanna and A. J. Nozik, "Solar conversion efficiency of photovoltaic and photoelectrolysis cells with carrier multiplication absorbers," Journal of Applied Physics, vol. 100, no. 7, Article ID 074510, 2006.

[32] R. D. Schaller, M. Sykora, J. M. Pietryga, and V. I. Klimov, "Seven excitons at a cost of one: redefining the limits for conversion efficiency of photons into charge carriers," Nano Letters, vol. 6, no. 3, pp. 424-429, 2006.

[33] P. Smith, R. Singh, and J. Dubow, "Reverse current-voltage characteristics of indium tin oxide/silicon solar cells under illumination," Journal of Applied Physics, vol. 51, no. 4, pp. 2164-2166, 1980.

[34] T. Trupke, M. A. Green, and P. Würfel, "Improving solar cell efficiencies by down-conversion of high-energy photons," Journal of Applied Physics, vol. 92, no. 3, pp. 1668-1674, 2002.

[35] T. Trupke, M. A. Green, and P. Würfel, "Improving solar cell efficiencies by up-conversion of sub-band-gap light," Journal of Applied Physics, vol. 92, no. 7, pp. 4117-4122, 2002.

[36] C. Strümpel, M. McCann, G. Beaucarne, et al., "Modifying the solar spectrum to enhance silicon solar cell efficiencyan overview of available materials," Solar Energy Materials and Solar Cells, vol. 91, no. 4, pp. 238-249, 2007.

[37] V. Švrček, A. Slaoui, and J.-C. Muller, "Silicon nanocrystals as light converter for solar cells," Thin Solid Films, vol. 451-452, pp. 384-388, 2004.

[38] E. D. Jackson, "Areas for improvement of the semiconductor solar energy converter," in Transactions of the Conference on the Use of Solar Energy, vol. 5, pp. 122-126, University of Arizona Press, Tucson, Ariz, USA, 1958.

[39] K. W. J. Barnham and G. Duggan, "A new approach to high-efficiency multi-band-gap solar cells," Journal of Applied Physics, vol. 67, no. 7, pp. 3490-3493, 1990. 
[40] E.-C. Cho, S. Park, X. Hao, et al., "Silicon quantum dot/crystalline silicon solar cells," Nanotechnology, vol. 19, no. 24, Article ID 245201, 2008.

[41] B. O. Dabbousi, M. G. Bawendi, O. Onitsuka, and M. F. Rubner, "Electroluminescence from CdSe quantum-dot/polymer composites," Applied Physics Letters, vol. 66, pp. 1316-1318, 1995.

[42] M. J. Konstantinovic, S. Bersier, X. Wang, et al., "Raman scattering in cluster-deposited nanogranular silicon films," Physical Review B, vol. 66, no. 16, Article ID 161311, 4 pages, 2002.

[43] A. Khitun, A. Balandin, J. L. Liu, and K. L. Wang, "In-plane lattice thermal conductivity of a quantum-dot superlattice," Journal of Applied Physics, vol. 88, no. 2, pp. 696-699, 2000.

[44] W. L. Liu, T. Borca-Tasciuc, G. Chen, J. L. Liu, and K. L. Wang, "Anisotropic thermal conductivity of Ge quantumdot and symmetrically strained Si/Ge superlattices," Journal of Nanoscience and Nanotechnology, vol. 1, no. 1, pp. 39-42, 2001.

[45] V. A. Belyakov, V. A. Burdov, R. Lockwood, and A. Meldrum, "Silicon nanocrystals: fundamental theory and implications for stimulated emission," Advances in Optical Technologies, vol. 2008, Article ID 279502, 32 pages, 2008.

[46] M. Wolf, "Limitations and possibilities for improvement of photovoltaic solar energy converters-part I: considerations for earth's surface operation," Proceedings of the IRE, vol. 48, pp. 1246-1262, 1960.

[47] A. Luque and A. Martí, "Increasing the efficiency of ideal solar cells by photon induced transitions at intermediate levels," Physical Review Letters, vol. 78, no. 26, pp. 5014-5017, 1997.

[48] A. Martí, N. López, E. Antolín, et al., "Novel semiconductor solar cell structures: the quantum dot intermediate band solar cell," Thin Solid Films, vol. 511-512, pp. 638-644, 2006.

[49] K. M. Yu, W. Walukiewicz, J. Wu, et al., "Diluted II-VI oxide semiconductors with multiple band gaps," Physical Review Letters, vol. 91, no. 24, Article ID 246403, 4 pages, 2003.

[50] E. Antolín, A. Martí, J. Olea, et al., "Lifetime recovery in ultra highly titanium-doped silicon for the implementation of an intermediate band material," Applied Physics Letters, vol. 94, Article ID 042115, 2009.

[51] A. G. Norman, M. C. Hanna, P. Dippo, et al., "InGaAs/GaAs QD superlattices: MOVPE growth, structural and optical characterization, and application in intermediate-band solar cells," in Proceedings of the 31st IEEE Photovoltaic Specialists Conference, pp. 43-48, 2005.

[52] Y. Chiba, A. Islam, Y. Watanabe, R. Komiya, N. Koide, and L. Han, "Dye-sensitized solar cells with conversion efficiency of 11.1\%," Japanese Journal of Applied Physics, vol. 45, no. 24-28, pp. L638-L640, 2006.

[53] J. Krüger, R. Plass, M. Grätzel, P. J. Cameron, and L. M. Peter, "Charge transport and back reaction in solid-state dyesensitized solar cells: a study using intensity-modulated photovoltage and photocurrent spectroscopy," Journal of Physical Chemistry B, vol. 107, no. 31, pp. 7536-7539, 2003.

[54] P. Yang, "Nanowire-based solar cell," in Proceedings of the APS March Meeting, 2006, Session G10.00001.

[55] M. Law, L. E. Greene, J. C. Johnson, R. Saykally, and P. Yang, "Nanowire dye-sensitized solar cells," Nature Materials, vol. 4, no. 6, pp. 455-459, 2005.

[56] L. E. Greene, M. Law, B. D. Yuhas, and P. Yang, "ZnO$\mathrm{TiO}_{2}$ core-sheath nanorod/P3HT solar cell," Journal of Physical Chemistry C, vol. 111, no. 50, pp. 18451-18456, 2007.

[57] M. Law, L. E. Greene, A. Radenovic, T. Kuykendall, J. Liphardt, and $\mathrm{P}$. Yang, " $\mathrm{ZnO}-\mathrm{Al}_{2} \mathrm{O}_{3}$ and $\mathrm{ZnO}-\mathrm{TiO}_{2}$ core-shell nanowire dye-sensitized solar cells," Journal of Physical Chemistry B, vol. 110, no. 45, pp. 22652-22663, 2006.

[58] Z. V. Vardeny, A. J. Heeger, and A. Dodabalapur, "Fundamental research needs in organic electronic materials," Synthetic Metals, vol. 148, pp. 1-3, 2005.

[59] Y. K. Jin, K. Lee, N. E. Coates, et al., "Efficient tandem polymer solar cells fabricated by all-solution processing," Science, vol. 317, no. 5835, pp. 222-225, 2007.

[60] A. Lodha and R. Singh, "Prospects of manufacturing organic semiconductor-based integrated circuits," IEEE Transactions on Semiconductor Manufacturing, vol. 14, no. 3, pp. 281-296, 2001.

[61] M. J. Kelly, "Are quantum semiconductor devices delivering?" Materials Science and Engineering B, vol. 35, no. 1-3, pp. 1-6, 1995.

[62] M. LaPedus and P. Clarke, "Motorola closes GaAson-silicon wafer subsidiary," EE Times, January 2003, http://www.eetimes.com/news/semi/showArticle.jhtml?article $\mathrm{ID}=10800321$

[63] M. Kanellos, “Inside OptiSolar's Grand Ambitions,” April 2009, http://www.greentechmedia.com/articles/read/insideoptisolars-grand-ambitions-6029/.

[64] R. Singh, unpublished results. 


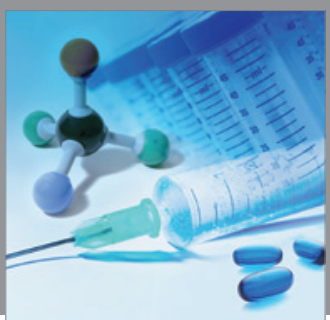

International Journal of

Medicinal Chemistry

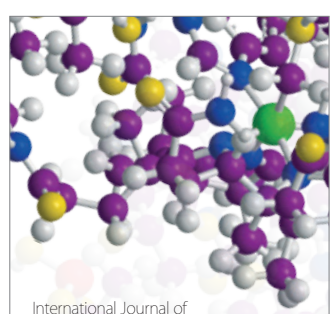

Carbohydrate Chemistry

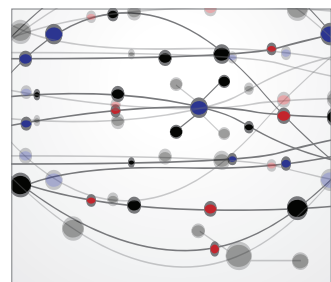

The Scientific World Journal
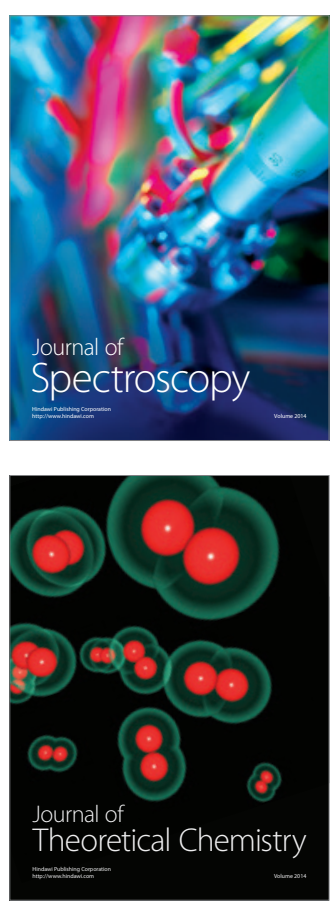
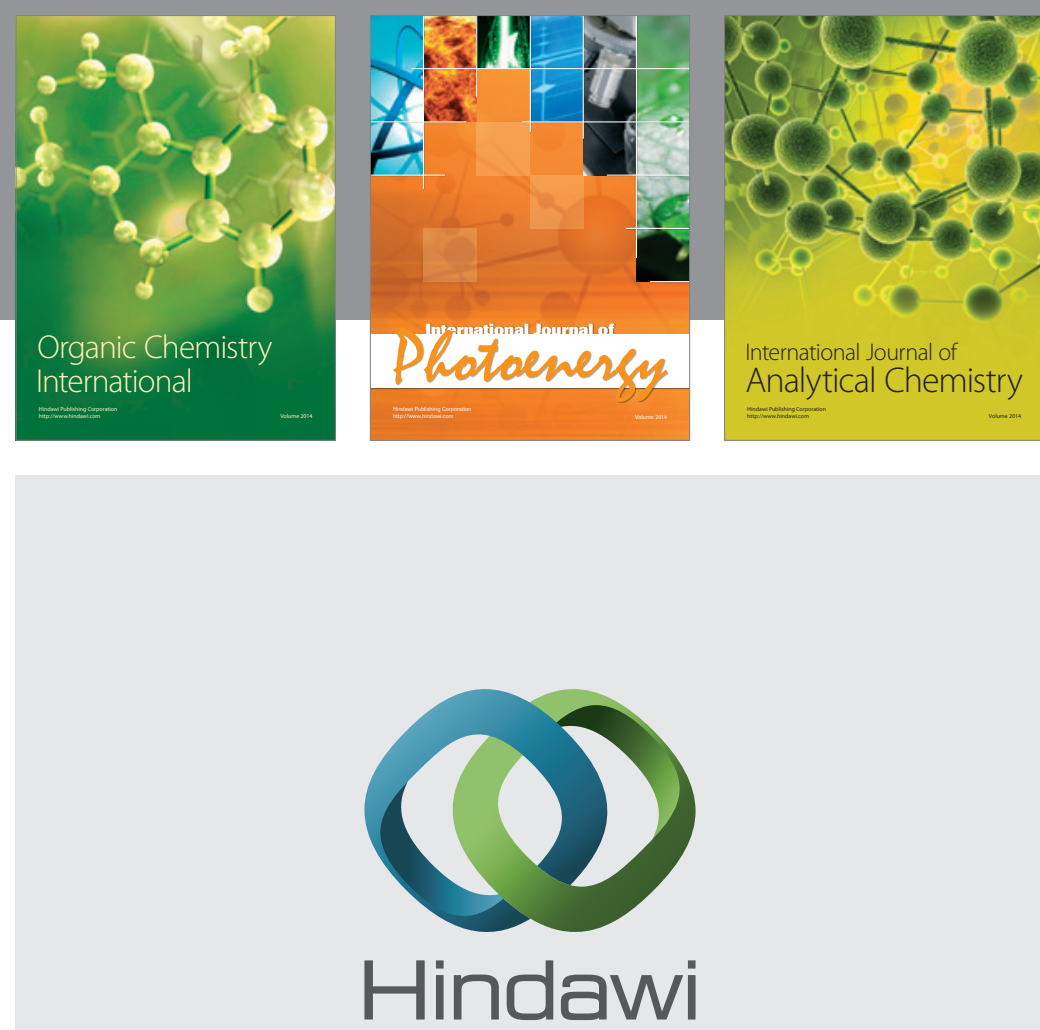

Submit your manuscripts at

http://www.hindawi.com
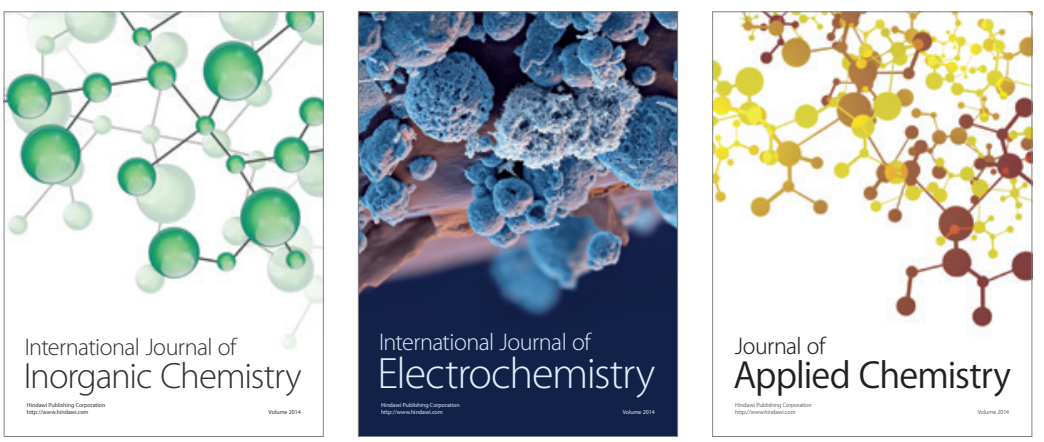

Journal of

Applied Chemistry
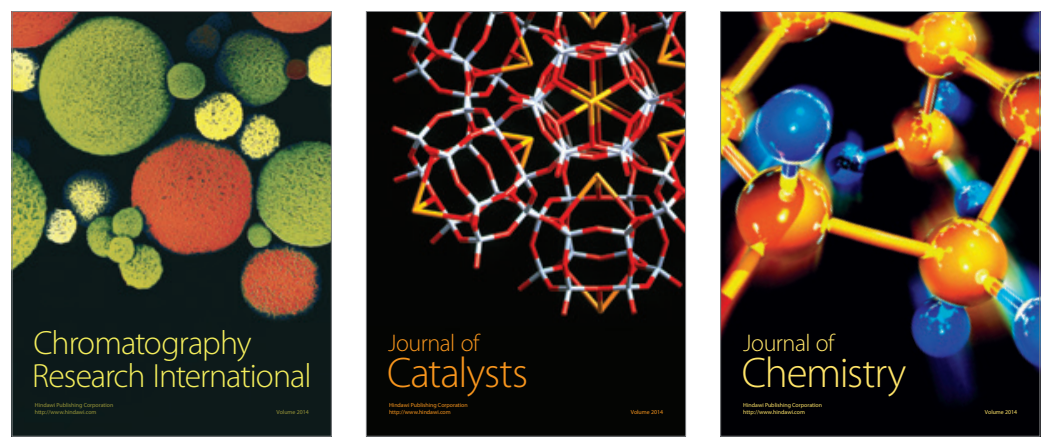
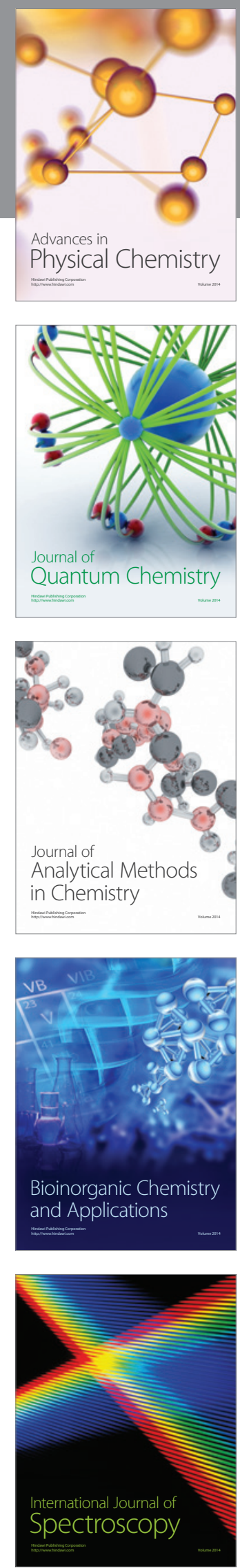